\title{
PENINGKATAN KETERAMPILAN GURU IPA SD AL AZHAR DALAM PEMBUATAN SOAL OLIMPIADE
}

\author{
Ade Suryanda1), Eka Putri Azrai1), Subari²) \\ 1)Program Studi Pendidikan Biologi, FMIPA, Universitas Negeri Jakarta, Jakarta, Indonesia \\ ${ }^{2)}$ Seksi Kurikulum dan Pengembangan Program SD Islam Al Azhar, Jakarta, Indonesia \\ Corresponding author : Ade Suryanda \\ E-mail : asuryanda@unj.ac.id
}

Diterima 24 Desember 2019, Disetujui 5 April 2020

\begin{abstract}
ABSTRAK
Pelatihan Olimpiade Sains bagi guru-guru Al Azhar jenjang Sekolah Dasar ini merupakan wadah pembinaan spiritual, mental, dan kompetensi olimpiade. Kegiatan ini bertujuan meningkatkan kompetensi guru dalam; 1) menganalisis silabus OSN tingkat nasional; 2) mengadaptasikan soal-soal OSN tingkat Nasional; dan 3) menyusun soal-soal OSN. Pelatihan menggunakan metode experiential learning dengan pendekatan participant-centered melalui teknik diskusi, tanya jawab, brainstorming, observasi, kerja kelompok dan presentasi hasil. Pada kegiatan ini dilakukan tahapan; 1) Analisis silabus OSN tingkat nasional; 2) Adaptasi soal-soal OSN tingkat Nasional; dan 3) Penyusunan soal-soal OSN. Pelatihan ini berjalan dengan baik dan memberikan manfaat yang signifikan serta terdapat meningkatkan keterampilan guru dalam membuat soal olimpiade.
\end{abstract}

Kata kunci: brainstorming; experiental learning; guru; OSN; pelatihan.

ABSTRACT
The Science Olympiad Training Al Azhar elementary school teachers for 2019 is a forum for spiritual, mental and Olympic competence development. This activity aims to improve teacher competency in; 1 ) analyze the national level The Science Olympiad syllabus; 2) adapt National level The Science Olympiad questions; and 3) compile The Science Olympiad questions. The training uses experiential learning methods with participant-centered approach through discussion techniques, question and answer, brainstorming, observation, group work and presentation of results. In this activity carried out stages; 1) National level The Science Olympiad syllabus analysis; 2) Adaptation of National Level The Science Olympiad questions; and 3) Compilation of The Science Olympiad questions. This training ran well and provided significant benefits as well as increasing teacher skills in making Olympic questions.

Keywords: brainstorming; experiential learning; National Science Olympiad; teachers; training.

PENDAHULUAN

Olimpiade Sains Nasional untuk peserta didik SD/MI dan atau yang sederajat ini diselenggarakan untuk memotivasi para peserta didik, guru, pengelola, dan pembina pendidikan untuk berkompetisi secara sehat dengan mengedepankan sportivitas guna mencapai prestasi terbaik, sekaligus meningkatkan kualitas pendidikan di daerah masing-masing. Peningkatan prestasi siswa di kancah Nasional dan Internasional menjadi sorotan penting dalam proses pembinaan guru pada bidang sains kepada para siswa yang memiliki bakat dan minat dibidang sain. Guru pembina sains berperan aktif untuk memberikan pembinaan secara intensif dan berkelanjutan kepada para siswanya dalam rangka partisipasi mereka pada kegiatan OSN disetiap jenjangnya (Dirjen Dikdasmen, 2019;
Muliani, Noviati, \& Fajriani, 2018; Wiyoko \& Avana, 2019).

Pembelajaran IPA sangat berperan dalam proses pendidikan dan juga perkembangan teknologi. Sains yang diajarkan sesuai dengan hakikatnya, yaitu sebagai proses, produk, sikap, dan teknologi akan menjadi sarana untuk mengembangkan aspek kognitif, afektif, dan keterampilan proses sains melalui rentetan pembelajaran di bangku sekolah. Pembelajaran sains atau ilmu pengetahuan alam merupakan sebuah kegiatan pembelajaran yang berorientasi pada lingkungan alam. Pembelajaran ini bertujuan untuk memberikan kepekaan dan juga perhatian bagi para peserta didik untuk dapat mengenali secara lebih mendalam tentang lingkungan alam (Rahayu, Mulyani, \& Miswadi, 2012; Tursinawati, 2017; Desstya, 2014) 
Upaya penguatan pondasi tersebut harus ditempuh dengan mewujudkan Pendidikan yang berorientasi pada peserta didik agar mampu berkreasi dan memecahkan masalah yang dihadapi dalam kehidupan sehari-hari. Oleh karena itu, paradigma pendidikan yang mengedepankan peningkatan daya nalar, kreativitas, kemampuan berpikir kritis dan sadar terhadap lingkungan harus diaplikasikan dalam setiap langkah pengembangan ke depan (Dirjen Dikdasmen, 2019). Upaya ini akan sangat berhasil apabila ditunjang oleh tenaga pendidikan yang mumpuni.

Pada dasarnya guru SD adalah guru kelas, dalam arti bukan guru bidang studi. Sebagian besar guru SD mengajar lebih dari satu mata pelajaran, dengan latarbelakang pendidikan yang bervariasi. Guru mempunyai tugas mulai dari merencanakan pembelajaran, pemilihan metode dan strategi, penggunaan media, pelaksanaan pembelajaran sampai evaluasi, yang merupakan tugas yang cukup berat. Kebanyakan guru maupun siswa akan mengalami kesulitan menyelesaikan masalah atau soal-soal olimpiade jika tidak pernah belajar untuk memecahkan masalah (Fitrianawati \& Sintawati, 2018).

Berdasarkan analisis situasi yang berkembang saat ini, permasalahan utama yang dihadapi guru IPA SD yaitu: 1) Kesulitan guru menganalisis materi yang terkait dengan soal olimpiade; 2) Terdapat beberapa Guru pembimbing olimpiade di sekolah masih belum memiliki keterampilan dalam menganalisis dan menyelesaikan soal olimpiade, baik soal olimpiade tingkat kabupaten/kota, provinsi bahkan nasional

Berdasarkan permasalahan tersebut, maka pelaksanaan kegiatan ini adalah upaya untuk memberikan solusi kepada guru, dengan memberikan pelatihan serta pembinaan melalui pendalaman materi, pembahasan soal, analisis silabus dengan soal OSN serta melihat tingkat kesulitan materi soal olimpiade, kemudian diakhiri dengan pelatihan membuat soal setingkat OSN.

\section{METODE}

Pelaksanaan kegiatan menerapkan
metode pembelajaran pengalaman (experiential learning) (Dennison, 2012; Knowles, 1978; Kolb, Boyatzis, \& Mainemelis, 2014; Moon, 2014; Lieb, 1991). Menggunakan filosofi pendidikan orang dewasa (Knowles, 1978; Sunhaji, 2013) sehingga nara sumber hanya sebagai fasilitator, yang berfungsi sebagai pengarah dan perancang pengalaman belajar. Program pelatihan ini lebih banyak melibatkan aktifitas peserta melalui diskusi, tanya jawab, brainstorming, observasi, kerja kelompok dan presentasi hasil. Pelibatan peserta secara aktif ditujukan supaya peseta tidak bosan dan tidak merasa digurui. Para guru yang telah ikut kegiatan diharapkan dapat menularkan ketrampilan ke guru-guru lainnya.

\section{HASIL DAN PEMBAHASAN}

Kegiatan yang diadakan di Griya Dharma Wulan Hotel, Darmawan Park Bogor ini diikuti oleh 28 guru IPA SD, yang berasal dari 28 Sekolah Dasar Islam Al Azhar se Indonesia. Mereka merupakan pembina-pembina olimpiade IPA di sekolah masing-masing seperti yang terlihat Gambar 1.

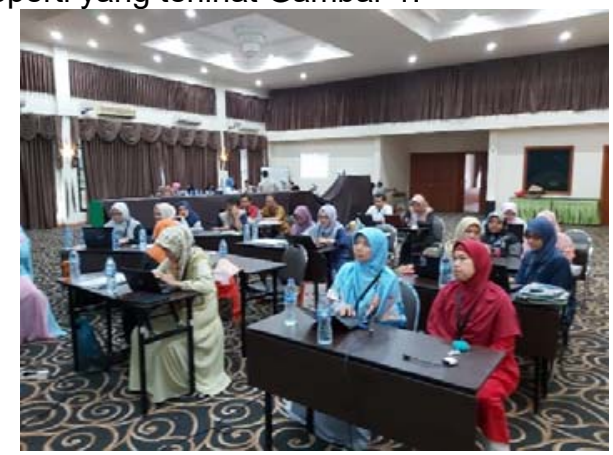

Gambar 1. Peserta Kegiatan

Kegiatan pembinaan diawali dengan paparan narasumber seputar Olimpiade Sain, mulai dari sejarah, kerangka dasar olimpiade dan strategi pembuatan soal yang umumnya dilakukan oleh tim pembuat soal berdasarkan silabus 2019. Selain itu juga dipaparkan silabus OSN berdasarkan petunjuk pelaksanaan OSN 2019. Setelah itru paparan dilanjutkan strategi sekolah dalam melakukan rekrutmen peserta OSN dan strategi pembinaan.

Kegiatan dilanjutkan dengan melakukan kerja mandiri oleh masing-masing peserta. Para peserta melakukan analisis dan pemetaan soal-soal OSN mulai tahun 2017, 2018, dan 2019. Soal-soal tersebut dianalisis berdasarkan konsep-kansep sains dan silabus OSN. Contoh hasil yang dikerjakan peserta dapat dilihat pada Gambar 2. Setelah melakukan analisis tersebut, peserta mempresentasikan dan mendiskusikan hasil tersebut, seperti terlihat pada Gambar 3. 


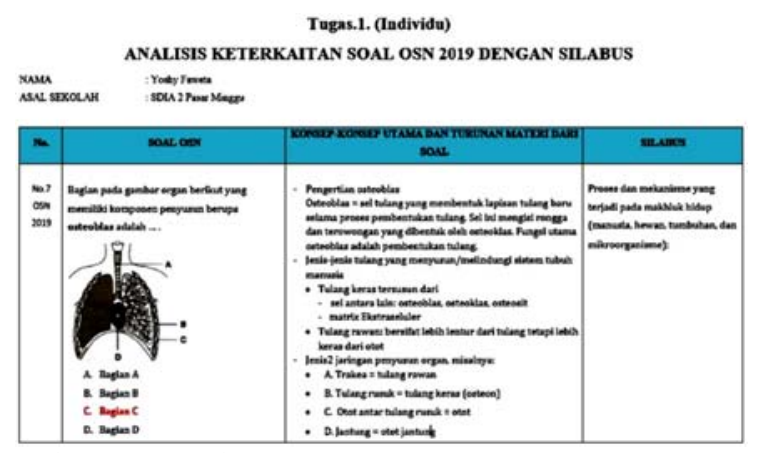

Gambar 2. Salah satu contoh hasil analisis oleh guru

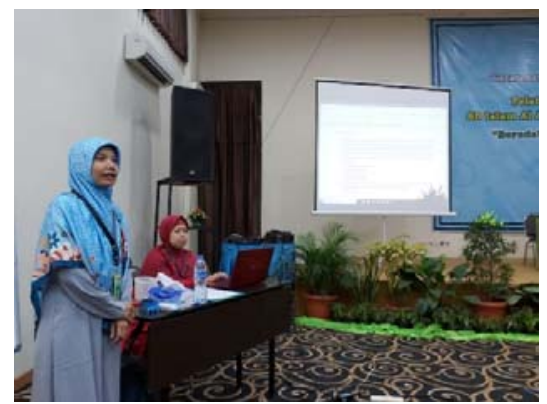

Gambar 3. Peserta sedang memaparkan hasil analisis soal

Kegiatan dilanjutkan dengan kerja kelompok membuat soal olimpiade, yang sebelumnya kepada peserta narasumber memberikan beberapa sumber rujukan pembuatan soal, baik dari majalah sains, maupun buku-buku rujukan yang layak. Sumber-sumber ini dapat diakses dengan mudah oleh peserta. Contoh rujukan dapat dilihat pada Gambar 4. Kegiatan pembuatan soal dilanjutkan dengan presentasi dan diskusi serta mendapatkan masukan dari peserta dan nara sumber Gambar 5.

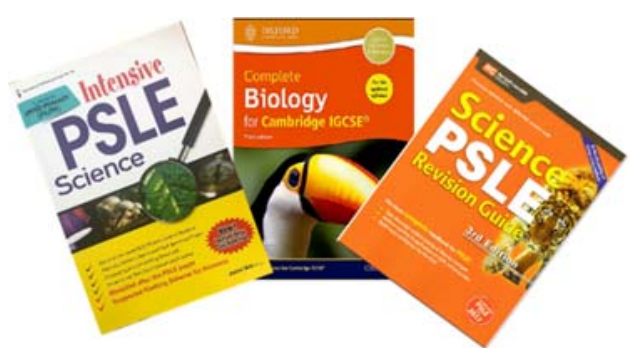

Gambar 4. Contoh buku rujukan yang digunakan

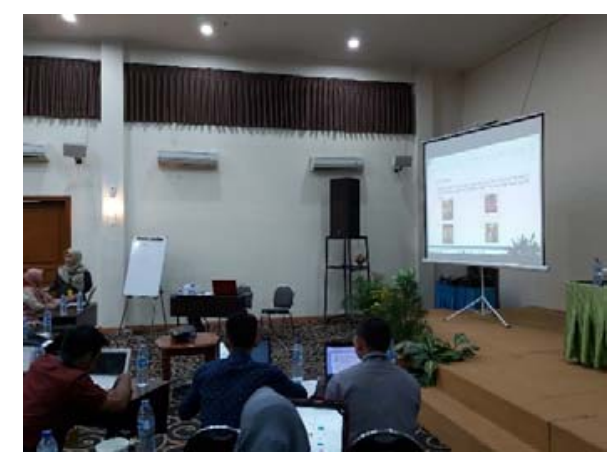

Gambar 5. Presentasi Soal Olimpiade Karya Peserta

\section{SIMPULAN DAN SARAN}

Kegiatan "Peningkatan Keterampilan Guru IPA SD Al Azhar dalam Pembuatan Soal Olimpiade" telah berjalan dengan baik dan memberikan manfaat yang signifikan serta terdapat peningkatan keterampilan guru dalam membuat soal olimpiade. Tingkat partisipasi peserta yang tinggi terlihat dari keterlibatan penuh peserta dalam kegiatan.

Kegiatan ini sangat diperlukan dan perlu berkesinambungan, sehingga disarankan agar kegiatan ini di tindak lanjuti pada sekolah masing-masing dengan membentuk Tim Pembina Olimpiade sekolah, yang rutin dipertemukan dalam skala nasional oleh Yayasan Pendidikan Islam Al Azhar.

\section{UCAPAN TERIMA KASIH}

Ucapan terima kasih TIM sampaikan kepada Direktorat Pendidikan Dasar dan Menengah, Yayasan Pesantren Islam Al Azhar, yang telah memfasilitasi kegiatan "Peningkatan Keterampilan Guru IPA SD Al Azhar dalam Pembuatan Soal Olimpiade".

\section{DAFTAR RUJUKAN}

Dennison, P. (2012). Reflective practice: The enduring influence of Kolb's Experiential Learning Theory. Compass: Journal of Learning and Teaching, 1(1), 1-6. https://doi.org/10.21100/compass.v1i1. 12

Desstya, A. (2014). Kedudukan dan Aplikasi Pendidikan Sains di Sekolah Dasar. Profesi Pendidikan Dasar, 1(2), 193200.

Dirjen Dikdasmen. (2019). Petunjuk Pelaksanaan Olimpiade Sains Nasional tingkat Sekolah Dasar Tahun 2019. Jakarta: Kementerian Pendidikan dan Kebudayaan.

Fitrianawati, M., \& Sintawati, M. (2018). Peningkatan Kompetensi Guru Pembimbing Olimpiade Matematika Siswa Sekolah Dasar Sekecamatan 
Tempel. Sniemas Uad 2018, 205-210.

Knowles, M. S. (1978). Community College Review Andragogy: Adult Learning Theory in Perspective. 9-20. https://doi.org/10.1177/009155217800 500302

Kolb, D. A., Boyatzis, R. E., \& Mainemelis, C. (2014). Experiential learning theory: Previous research and new directions. Perspectives on Thinking, Learning, and Cognitive Styles, (216), 227-247. https://doi.org/10.4324/978141060598 6-9

Lieb, S. (1991). Principles of adult learning , Phoenix , AZ : Vision - South Mountain Community College ,.

Moon, J. A. (2014). A Handbook of Reflective and Experiential Learning. In $A$ Handbook of Reflective and Experiential Learning. https://doi.org/10.4324/978020341615 0

Muliani, F., Noviati, D., \& Fajriani. (2018). Pembinaan Peningkatan Mutu Pendidikan Bidang Olimpiade Sains Bagi Guru Sd Kota Langsa Provinsi Aceh. Jurnal ABDIMAS Unmer Malang, 3(2), 9-13.

Rahayu, P., Mulyani, S., \& Miswadi, S. S. (2012). Pengembangan pembelajaran IPA terpadu dengan menggunakan model pembelajaran problem base melalui lesson study. Jurnal Pendidikan IPA Indonesia, 1(1), 63-70. https://doi.org/10.15294/jpii.v1i1.2015

Sunhaji. (2013). Konsep Pendidikan Orang Dewasa. Jurnal Kependidikan IAIN Purwokerto, 1(1), 1-11.

Tursinawati. (2017). Penguasaan Konsep Hakikat Sains Dalam Pelaksanaan Percobaan Pada Pembelajaran Ipa Di SDN Kota Banda Aceh. Jurnal Pesona Dasar, 2(4), 72-84.

Wiyoko, T., \& Avana, N. (2019). Peningkatan Kompetensi Siswa melalui Pembinaan Olimpoiade. 22(2), 67-75. 